\title{
Novel mTORC1 Mechanism Suggests Therapeutic Targets for COMPopathies
}

Karen L. Posey, ${ }^{*}$ Francoise Coustry, ${ }^{*}$ Alka C. Veerisetty, ${ }^{*}$ Mohammad G. Hossain, ${ }^{*}$ Michael J. Gambello, ${ }^{\dagger}$ and Jacqueline T. Hecht**

From the Department of Pediatrics, * McGovern Medical School, and the School of Dentistry, ${ }^{\ddagger}$ University of Texas Health Science Center, Houston, Texas; and Human Genetics and Pediatrics, ${ }^{\dagger}$ Emory University School of Medicine, Atlanta, Georgia

Accepted for publication September 17, 2018.

Address correspondence to Karen L. Posey, Ph.D., Department of Pediatrics, McGovern Medical School at The University of Texas Health Science Center at Houston (UTHealth), 6431 Fannin St. Houston, TX 77030. E-mail: karen.posey@uth.tmc.edu.

\begin{abstract}
Cartilage oligomeric matrix protein (COMP) is a large, multifunctional extracellular protein that, when mutated, is retained in the rough endoplasmic reticulum (ER). This retention elicits ER stress, inflammation, and oxidative stress, resulting in dysfunction and death of growth plate chondrocytes. While identifying the cellular pathologic mechanisms underlying the murine mutant (MT)-COMP model of pseudoachondroplasia, increased midline-1 (MID1) expression and mammalian target of rapamycin complex 1 (mTORC1) signaling was found. This novel role for MID1/mTORC1 signaling was investigated since treatments shown to repress the pathology also reduced Mid1/mTORC1. Although ER stressinducing drugs or tumor necrosis factor $\alpha(\mathrm{TNF} \alpha)$ in rat chondrosarcoma cells increased Mid1, oxidative stress did not, establishing that ER stress- or TNF $\alpha$-driven inflammation alone is sufficient to elevate MID1 expression. Since MID1 ubiquitinates protein phosphatase 2A (PP2A), a negative regulator of mTORC1, PP2A was evaluated in MT-COMP growth plate chondrocytes. PP2A was decreased, indicating de-repression of mTORC1 signaling. Rapamycin treatment in MT-COMP mice reduced mTORC1 signaling and intracellular retention of COMP, and increased proliferation, but did not change inflammatory markers IL-16 and eosinophil peroxidase. Lastly, mRNA from tuberous sclerosis-1/2-null mice brain tissue exhibiting ER stress had increased Mid1 expression, confirming the relationship between ER stress and MID1/mTORC1 signaling. These findings suggest a mechanistic link between ER stress and MID1/ mTORC1 signaling that has implications extending to other conditions involving ER stress. (Am J Pathol 2019, 189: 132-146; https://doi.org/10.1016/j.ajpath.2018.09.008)
\end{abstract}

Cartilage oligomeric matrix protein (COMP) is a large, pentameric extracellular matrix protein that is a member of the thrombospondin gene family. These proteins have adhesive properties that are known to mediate cell-cell and cell-matrix interactions. ${ }^{1-7}$ Reported functions of COMP include: i) production, maintenance, and homeostasis of cartilage, ii) regulation of type II collagen fibril assembly, and iii) enhancement of chondrocyte attachment and proliferation. $^{8-14}$ Interestingly, more is known about the results of mutant (MT)-COMP in growth plate chondrocytes than the functions of wild-type COMP. Mutations in COMP cause pseudoachondroplasia (PSACH), a severe dwarfing condition characterized by disproportionate short stature, joint laxity, pain, and early-onset osteoarthritis. ${ }^{2,10,15-36}$ $\mathrm{PSACH}$ is not evident at birth, being identified by 2 years of age, when slow linear growth leads to diagnosis. The hallmark of PSACH growth plate chondrocytes is massive retention of MT-COMP in rough endoplasmic reticulum (ER) cisternae. ${ }^{20}$ MT-COMP prematurely assembles into an ordered matrix composed of types II and IX collagen and matrilin-3 and other extracellular matrix proteins, resulting in intracellular protein accumulation. ${ }^{30,37,38}$ Approximately $97 \%$ of COMP pentamers are predicted to contain at least

Supported by the National Institute of Arthritis and Musculoskeletal and Skin Diseases, NIH grant RO1-AR057117-05 (J.T.H. and K.L.P.); and the Leah Lewis Family Foundation (J.T.H.).

Disclosures: None declared.

The content is solely the responsibility of the authors and does not necessarily represent the official views of the US National Institutes of Health. 
one mutant subunit causing a dominant negative effect that results in the protein being trapped in the ER. ${ }^{39}$ Ultimately, the rough ER of affected chondrocytes enlarge, filling the cytoplasmic space and being cytotoxic to growth plate chondrocytes. $2,20,32,34$

Previously, a doxycycline-inducible mouse model that expresses MT-COMP (D469del) in growth plate chondrocytes, and that recapitulates the clinical phenotype and chondrocyte pathology of PSACH, was generated, validated, and used to identify the pathologic mechanisms. ${ }^{38,40,41}$ Those studies showed that the retention of MT-COMP induced ER stress, initiating a self-perpetuating stress loop involving oxidative stress and inflammation, which led to DNA damage, necroptosis, and loss of growth plate chondrocytes. ${ }^{40-42}$ Although intracellular retention was detected as early as embryonic day 15, the loss of growth plate chondrocytes affected only postnatal long bone growth. ${ }^{38,41}$ By postnatal day (P) 14, COMP intracellular retention stimulated detectable chondrocyte loss that peaked between P21 and P28, when inflammation and oxidative stress are also at their highest levels. ${ }^{38,41}$

A number of novel observations related to changes in mRNA expression were made during the investigation of the development of the pathology in the MT-COMP growth plate chondrocytes. ${ }^{38,40,41}$ Of particular interest was the upregulation of a microtubule stabilizer, midline 1 (MID1), ${ }^{43}$ which was elevated in the transcriptome of MT-COMP mice from P1 to P28 at all ages. The maximal levels of Midl expression were correlated with high levels of intracellular retention of MT-COMP and chondrocyte death, ${ }^{41}$ suggesting a link between the MID1 and MTCOMP pathologic processes. Recent work has shown that persistent ER stress stimulates the stabilization of the microtubule network in an effort to maintain cellular viability. ${ }^{44,45}$ Moreover, this finding was intriguing since MID1 is a stimulator of mammalian target of rapamycin complex 1 (mTORC1) signaling. This association led to the assessment of the role of MID1 in the MT-COMP chondrocyte pathology.

\section{Material and Methods}

\section{Generation of Bigenic Mice and CHOP-Null Bigenic Mice}

The bigenic MT-COMP mice were generated using two plasmids, pTRE-COMP (coding sequence of human $\mathrm{COMP}+\mathrm{FLAG}$ tag driven by the tetracycline responsive element promoter) and pTET-On-Col II (reverse tetracycline-controlled transactivator coding sequence driven by a type II collagen promoter) as previously described. $^{38,41}$ Standard breeding was used to generate bigenic animals and bigenic animals in the CCAAT/ enhancer-binding protein-homologous protein (CHOP)null background. Genotypes of the transgenic offspring were verified by PCR. ${ }^{46}$ All mice in these studies were male. Mice were pre-/postnatally administered $500 \mathrm{ng} / \mathrm{mL}$ doxycycline through drinking water. All animal studies were approved by the Animal Welfare Committee at the University of Texas Health Science Center (Houston, TX).

\section{Microarray Analysis}

Total RNA was extracted from both hind-limb knee joints and purified using TRIzol and RNAeasy columns (Qiagen, Hilden, Germany). RNA (300 ng) was amplified using the Total Prep RNA Amplification Kit (Illumina, San Diego, CA), and microarray analysis was performed as previously described. $^{41}$ A $P$ value of $<0.05$ was considered significant.

\section{IHC Analysis}

Hind limbs from MT-COMP and C57BL/6 control mice were collected and tibial growth plates analyzed as previously described. ${ }^{38}$ Briefly, the limbs were fixed in $95 \%$ ethanol, and pepsin $(1 \mathrm{mg} / \mathrm{mL}$ in $0.1 \mathrm{~N} \mathrm{HCl})$ was used for antigen retrieval. MID1 (catalog number SC 55247; goat polyclonal M-16; Santa Cruz Biotechnologies, Dallas, TX; 1:400), protein phosphatase (PP)-2A (catalog number GTX 113523; rabbit polyclonal; Genetex, Irvine, CA; 1:200), tumor necrosis factor (TNF)- $\alpha$ (catalog number ab6671; rabbit polyclonal; Abcam, Cambridge, UK; 1:200), TNFrelated apoptosis-inducing ligand (TRAIL; catalog number ab42243; rabbit polyclonal; Abcam; 1:200), mTOR (catalog number 2976S; rabbit monoclonal; Cell Signaling Technology, Danvers, MA; 1:200), phosphorylated S6 ribosomal protein (pS6; catalog number 2215S; rabbit polyclonal; Cell Signaling Technology; 1:200), AKT (catalog number 3787S; rabbit monoclonal; Cell Signaling Technology; 1:200), glioma-associated oncogene homolog 2 (zinc finger protein) (Gli2; catalog number PA1-28838; rabbit polyclonal; Invitrogen, Carlsbad, CA; 1:300), and parathyroid hormone-related peptide (PTHrP; catalog number SC-20728; rabbit polyclonal; Santa Cruz Biotechnologies; 1:300) antibodies were incubated with sections overnight at $4^{\circ} \mathrm{C}$ for immunostaining. Species-specific secondary antibodies were incubated with sections for 50 minutes. Coverslips were mounted with ProLong Gold antifade reagent (Molecular Probes, Eugene, OR).

\section{Treatments to Induce ER and 0xidative Stress in RCS Cells}

Rat chondrosarcoma (RCS) cells $(300,000$ per $22.1-\mathrm{mm}$ well) were treated with tunicamycin, thapsigargin, or peroxynitrite. ER stress was induced by either tunicamycin or thapsigargin. Tunicamycin was added to culture media $(0.1$, $0.5,1,1.5$, and $2 \mathrm{mg} / \mathrm{mL}$ ) and incubated for 8 hours. Thapsigargin treatment was 36 hours of exposure of 0.001 , $0.05,0.4$, or $0.8 \mu \mathrm{mol} / \mathrm{L}$ thapsigargin. Oxidative stress was induced by peroxynitrite treatment of 5, 50, 200, or $1000 \mathrm{mmol} / \mathrm{L}$ for 4 hours. RCS cells were harvested after 
treatments and RNA prepared for RT-PCR analysis. All experiments were repeated in triplicate.

\section{TNF $\alpha$ Treatment of RCS Cells to Evaluate Mid1 and Trail Responses}

RCS cells $(300,000$ per 22.1-mm well) were treated with $200 \mathrm{ng} / \mathrm{mL}$ murine TNF $\alpha$ (PeproTech, Rocky Hill, NJ) for 24 or 72 hours. RCS cells were harvested after TNF $\alpha$ treatment, and RNA was prepared for RT-PCR analysis.

\section{mRNA Quantification}

RNA was prepared as previously described. ${ }^{40}$ Quantitative real-time RT-PCR was performed utilizing the ABI-7900 RT-PCR system (Applied Biosystems, Foster City, CA). Each assay was replicated three times, and each sample was measured in triplicate. The data were normalized to Gapdh (percentage of the normalizer transcript). The following primers were used in this study: $M T$-COMP, 5'-GCAATGACACCATCCCAGAG-3' (forward) and $5^{\prime}$-CTTGTCATCGTCGTCCTTGTAGTC-3' (reverse); Chop, 5'-CCAGCAGAGGTCACAAGCAC-3' (forward) and $5^{\prime}$-CGCACTGACCACTCTGTTTC-3' (reverse); Gadd34, 5'-AATCAGGACCCTGAGATTCCT-3' (forward) and $5^{\prime}$-CTGGTCCTGCCCAGACAG-3' (reverse); Gadd45a, 5'-CCGAAAGGATGGACACGGTG-3' (forward) and $5^{\prime}$-TTATCGGGGTCTACGTTGAGC-3' (reverse); Erolb, 5'-CAAGGAAGCCAACCTCCTT-3' (forward) and 5'-GTGTTTCGTCCACTGAAGAAC- $3^{\prime}$ (reverse); Midl, 5'-CACTATACTGTGCATGGCCTAC- $3^{\prime}$ (forward) and $5^{\prime}$-TCGATGAGCAGATTTGGGATC- $3^{\prime}$ (reverse); Trail, 5'-ACTCCAAAATCGGACTAGCTTG-3' (forward) and 5'-TCTCAAAGGTTCTCAAAGTCACC-3' (reverse); Gapdh, 5'-AGTTCAACGGCACAGTCAAG- $3^{\prime}$ (forward) and 5'-TACTCAGCACCAGCATCACC- $3^{\prime}$ (reverse).

\section{Human Chondrocyte Nodule Culture}

Cartilage nodules were established and maintained from control and D469del, G427E, and D511Y chondrocytes as previously described. ${ }^{2,33}$ The nodules were collected after 6 weeks in culture, fixed in $4 \%$ paraformaldehyde, embedded in paraffin, and sectioned for immunohistochemistry analysis.

\section{Generation of RCS Cells That Express Human D469del- MT-COMP}

RCS cells expressing human D469del-MT-COMP were generated using the Lenti-X-Tet-On advanced inducible expression system according to the manufacturer's protocol (Takara Bio Company, Mountain View, CA). Briefly, RCS cells were infected with high-level lentiviral preparations of pLVX-Tet-On advanced vector or pLVX-Tight-human D469del-MT-COMP vector; at a multiplicity of infection value of 1 to ensure that single-colony integrants could be isolated. Cells were cultured for 3 days in nonselective media. Puromycin and G418 were then added to the media for the selection of stable integrants. Single colonies were moved to separate dishes and grown in standard culture media with G418 and puromycin for these experiments. The expression of human D469del-MT-COMP in RCS cells was validated by Western blot with anti-Flag antibody for the recognition of the tagged D469del-MT-COMP (catalog number F7425 rabbit polyclonal; Sigma-Aldrich, Saint Louis, MO; 1:5000).

\section{Mid1 siRNAs and Transfection}

RCS cells expressing human D469del-MT-COMP were transfected with various concentrations of Midl siRNAs using Mission siRNA transfection reagent following the manufacturer's recommendations (catalog number S1452; Sigma-Aldrich). All siRNAs target rat Midl NM_022972 and were purchased from Sigma-Aldrich (Midl siRNA 84: SASI_Rn01_00087200 targets beginning at nucleotide 1528; Midl siRNA 86: SASI_Rn01_00087197 targets beginning at nucleotide 1051; Midl siRNA 88: SASI_Rn01_00087196 targets beginning at nucleotide 899; Midl siRNA 90: SASI_Rn01_00087198 targets beginning at nucleotide 903). RCS cells were harvested after treatments and RNA prepared for RT-PCR analysis.

\section{MID1 Overexpression}

RCS cells expressing human D469del-MT-COMP were transfected with $1.5 \mu \mathrm{g}$ of MID1-overexpression plasmid pCS2-xMID1 ${ }^{47}$ (kindly provided by Dr. Makoto Suzuki) using Fugene 6 reagent (Promega, Madison, WI) according to the manufacturer's protocol. After treatments, RCS cells were harvested and RNA prepared for RT-PCR analysis.

\section{Results}

\section{MT-COMP Increases MID1 Expression}

To identify the molecular mechanisms that underlie the MTCOMP chondrocyte pathology, transcriptome analysis was performed. ${ }^{41}$ RNA was collected from the hind-limb knee joints of MT-COMP and control mice at P1, P7, P14, P21, and P28 and subjected to microarray expression analysis. Midl transcript level was significantly increased in MT-COMP mice at all ages compared to controls (Figure 1A). This increase was confirmed by quantitative real-time RT-PCR (data not shown), and immunostaining of MT-COMP growth plate chondrocytes showed increases in Mid1 protein in MT-COMP compared to the controls at all ages (Figure 1, B-I).

It was next determined whether this increase in MID1 expression was also present in human PSACH chondrocytes. Cartilage nodules grown in three-dimensional 

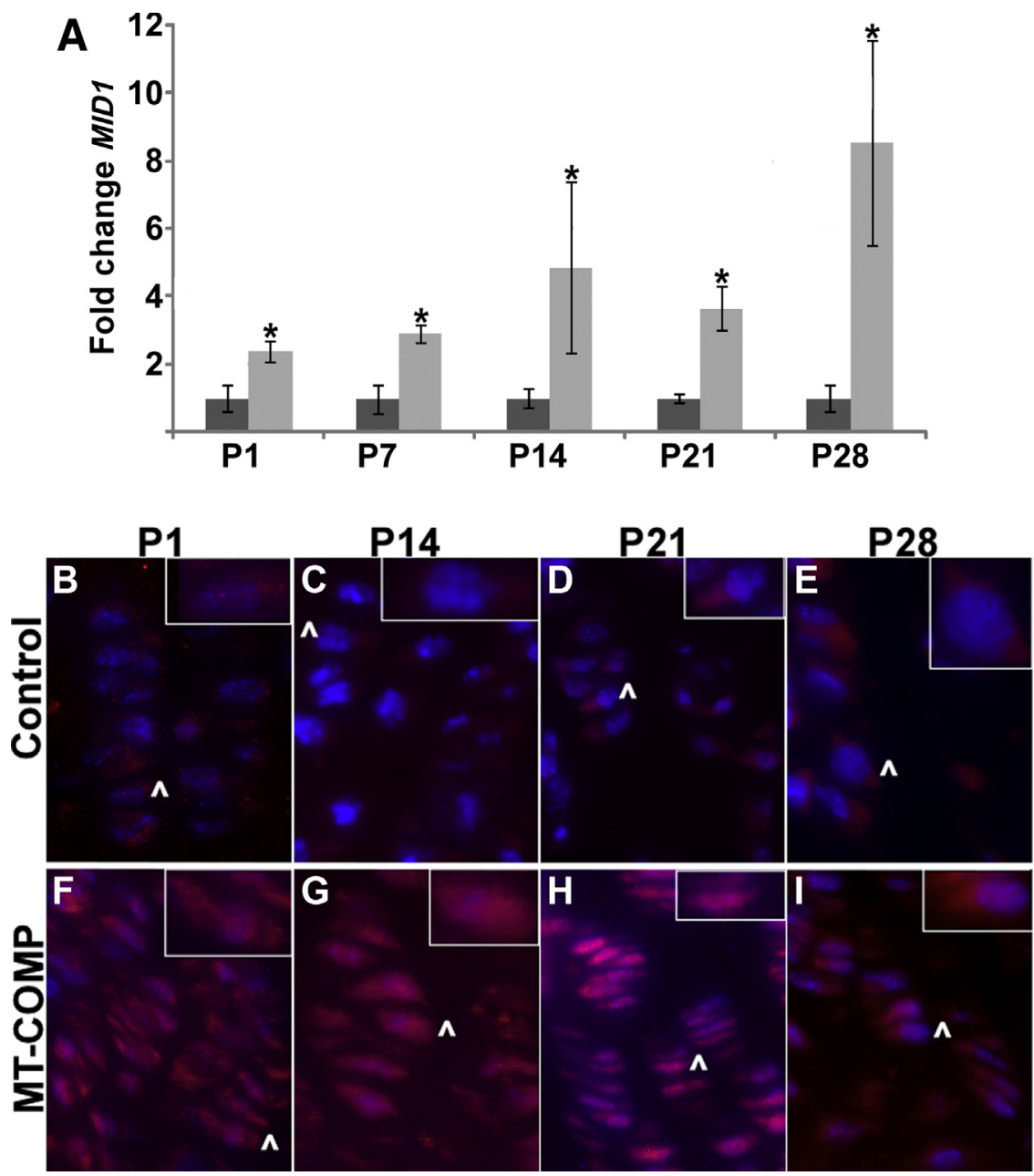
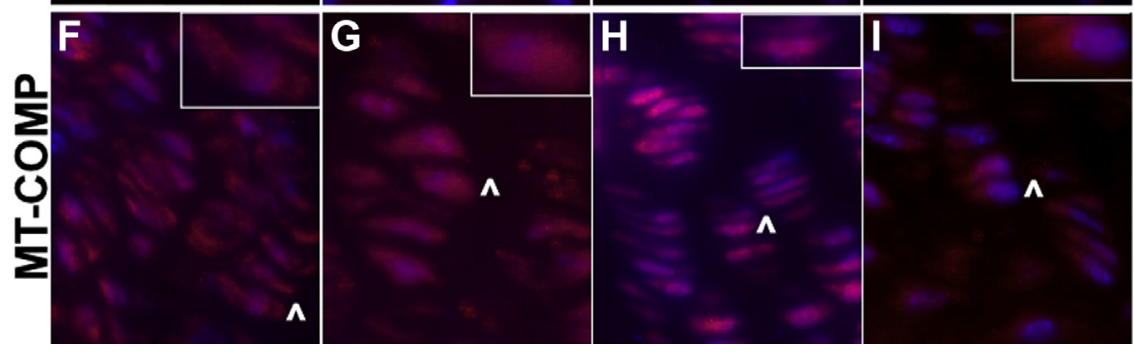

Figure 1 Midline 1 (MID1) is up-regulated in mutant cartilage oligomeric matrix protein (MTCOMP) mouse growth plate chondrocytes. Mid1 mRNA level was assessed by microarray and Mid1 protein by immunohistochemistry from P1 to P28. A: Mid1 expression in C57BL/6 mice (control; dark gray bars) was set to 1 and compared with the level of Mid1 expression in the MT-COMP mice (light gray bars). Growth plate chondrocytes from P1 to P14 show more Mid1 mRNA in the MT-COMP chondrocytes compared to control. B-I: Immunostaining of control C57BL/6 and MT-COMP growth plates with Mid1 (red) and DAPI (blue) stained nuclei from P1 to P28. Arrowheads mark the cells that are enlarged in the insets. Data are expressed as means \pm SD. $n=3$ mice per group (A). ${ }^{\star} P<0.05$. Original magnification: $\times 400(\mathrm{~B}-\mathrm{I})$; $\times 800$ (insets). culture as previously described were used in these experiments. $^{24,29,33,48}$ The chondrocytes were obtained from iliac crest biopsies from PSACH patients with D469del, G427E, and D511Y COMP mutations. These chondrocytes retain MT-COMP in the ER, causing ER stress and recapitulating the chondrocyte pathology observed in chondrocytes from PSACH growth plate biopsies. ${ }^{24,29,33,48}$ MID1 immunostaining was increased in the PSACH chondrocytes when compared to control chondrocytes (Figure 2, A-L). These results indicate that increased MID1 expression is associated with the human MTCOMP/PSACH chondrocyte pathology.

\section{Mid1 Is Increased by ER Stress and TNF $\alpha$ /TRAIL Inflammation}

MID1 plays a role in microtubule stability, ${ }^{43}$ and recent findings indicate that chronic ER stress results in the stabilization of the microtubule network to sustain cellular viability. ${ }^{44,45}$ Excessively low or high microtubule stability is detrimental to cell viability, and chemotherapies exploit this microtubule stability to reduce cancer cell viability. ${ }^{49}$ In these experiments, it was tested whether three stressors (ie, ER stress, oxidative stress, or inflammation) involved in the MT-COMP pathology increases Midl in vitro. RCS cells, well-characterized cells that maintain a chondrogenic phenotype, ${ }^{50}$ were used in these experiments because the delivery of stressor molecules to the growth plate is not feasible. Tunicamycin and thapsigargin were used to stimulate ER stress. Tunicamycin has been reported to inhibit $\mathrm{N}$-linked glycosylation in the ER and to cause protein accumulation in the ER, thereby activating the unfolded protein response. ${ }^{51}$ In contrast, thapsigargin has been reported to inhibit the sarco-/endoplasmic reticulum $\mathrm{Ca}^{2+}$ ATPase, depleting $\mathrm{Ca}^{2+}$ in the ER and stimulating ER stress. ${ }^{51}$ In the present study, RCS cells treated with tunicamycin ( 0.1 to $2 \mu \mathrm{g} / \mathrm{mL}$ for 8 hours) had a 2 - to 3.5 -fold increase in Midl mRNA (Figure 2M and Supplemental Figure S1), whereas thapsigargin $(0.001$ to $0.8 \mu \mathrm{mol} / \mathrm{L}$ for 36 hours) treatment increased Midl 2- to 20-fold, accompanied by an increase in Chop (Figure 2M and Supplemental Figure S1). These results demonstrate that ER stress increases Midl levels in chondrocytes and suggest that ER stress generated by MT-COMP intracellular 


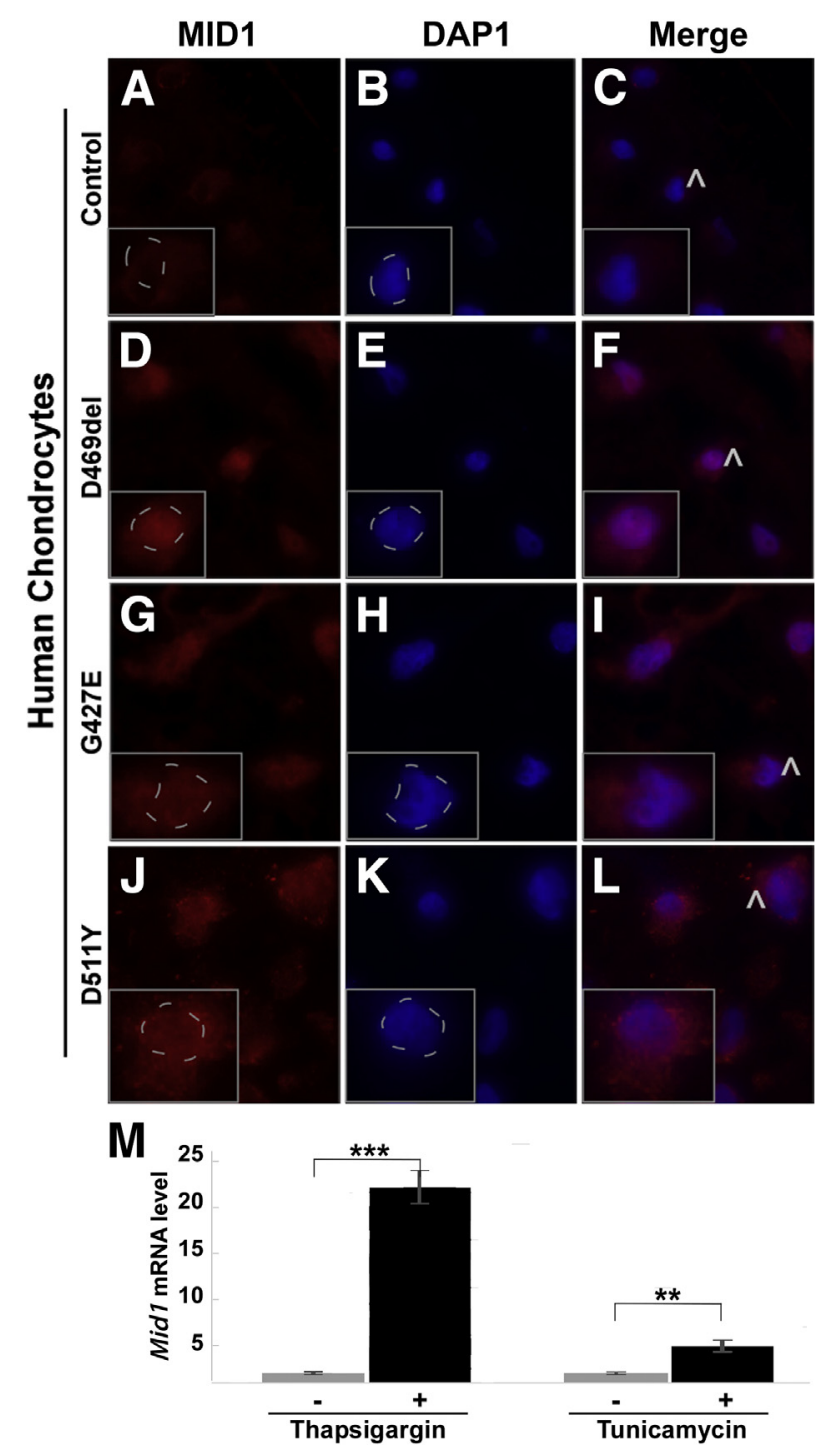

Figure 2 Midline (MID)-1 is increased in human pseudoachondroplasia (PSACH) chondrocytes and by endoplasmic reticulum stress in rat chondrosarcoma (RCS) cells. A-L: Chondrocytes from control and three different PSACH patients [with D511Y, G427E, and D469del cartilage oligomeric matrix protein (COMP) gene mutations] were grown in a three-dimensional culture system as previously described ${ }^{2,33}$ to generate nodules that were immunostained with MID1 antibody. DAPI (blue signal) marks the nuclei of chondrocytes. Arrowheads indicate the cells that are enlarged in the insets; dashed circles indicate the nuclei in the insets. M: Mid1 mRNA levels in RCS cells treated with thapsigargin or tunicamycin (gray bars) are compared to that in untreated cells (control; black bars). Data are expressed as means \pm SD. $n>100$ cells $(\mathbf{A}-\mathbf{L}) ; n=9$ (M). ${ }^{* *} P<0.005$, $* \star * P<0.0005$. Original magnification: $\times 600(\mathbf{A}-\mathbf{L}) ; \times 1500$ (insets).

retention increases MID1 levels in MT-COMP growth plate chondrocytes. Oxidative stress is also involved in the MT-COMP chondrocyte pathology. Peroxynitrite, an endogenous peroxide, was used to generate free-radical intermediates in RCS cells, and Midl mRNA levels were measured. ${ }^{52}$ Peroxynitrite treatment ( 5 to $1000 \mu \mathrm{mol} / \mathrm{L}$ for 4 hours) showed no significant increase in Midl mRNA (Supplemental Figure S1), suggesting that increases in Mid1 result from ER stress but not oxidative stress.
MT-COMP expression has been reported to be associated with the inflammatory process driven by TNF $\alpha$ and IL$1 \beta .^{42,53} \mathrm{TNF} \alpha / \mathrm{TRAIL}$ drive MID1 expression in asthma and esophageal eosinophilia. ${ }^{54,55}$ It was determined whether TNF $\alpha$ increases Trail and Midl independent of MT-COMP expression in RCS cells, as this TNF $\alpha$ increase in MID1 was previously shown in the epithelial cells lining the airway. ${ }^{55}$ $\mathrm{TNF} \alpha$ treatment $(200 \mathrm{ng} / \mathrm{mL})$ in RCS cells for 72 hours increased both Trail and Midl mRNAs by 33- and 16-fold, respectively (Figure 3K). Consistent with these findings, both TNF $\alpha$ and TRAIL immunostaining were also increased in MT-COMP mice compared to controls (Figure 3, A-J). These results demonstrate that ER stress and TNF $\alpha /$ TRAIL increased Midl in chondrocytes in vitro, and this finding is consistent with the up-regulation of Mid1 observed in MTCOMP mice growth plate chondrocytes.

\section{Increased MID1 Coincides with a Decrease in PP2A} Level and Increased mTORC1 Signaling in MT-COMP Chondrocytes

Since MID1 acts as a negative regulator of PP2A in many cell types, ${ }^{56,57}$ it was evaluated whether MID1 has a similar function in MT-COMP growth plate chondrocytes in mice. MID1 has been established as a ubiquitin ligase that targets PP2A for degradation, ${ }^{56,57}$ and therefore high levels of MID1 would be expected to decrease PP2A. PP2A was diminished in the MT-COMP growth plate, consistent with the role of MID1 as a negative regulator of PP2A (Figure 4, $\mathrm{A}-\mathrm{J}) .58,59$

MID1 is known to regulate mTORC1 but not mTORC2. ${ }^{60}$ Since MID1 is up-regulated in chondrocytes expressing MT-COMP and MID1 stimulates mTORC1, mTORC1 signaling and phosphorylated (p)-AKT were assessed in MT-COMP mice growth plates. $\mathrm{pS}^{61}$ and pmTOR were used as readouts for mTORC1 signaling and pAKT for activated AKT. MT-COMP growth plates at P28 showed strong pS6, pAKT, and pmTOR expression levels, which were absent in the controls (Figure 4, K-Y). MID1 modulates mTORC1 through at least two mechanisms: by regulating 3-phosphoinositide-dependent protein kinase (PDPK)-1 upstream of AKT and mTORC $1,{ }^{62}$ and regulating PP2A levels, which influences mTOR/regulatory associated protein of mTOR complex formation. ${ }^{60}$ These findings indicate that mTORC1 signaling is stimulated in MT-COMP mouse growth plate chondrocytes by increased levels of pAKT and repression of PP2A, which inhibits mTORC1 formation.

The tuberous sclerosis (TSC) mouse models, which lack $T s c 1, T s c 2$, or both, exhibit ER stress and increased mTORC1 signaling in their brain tissue. ${ }^{58,59}$ These TSC mice were used to test whether Midl was increased in the context of elevated ER stress and mTORC1 signaling in TSC mice (Figure 4Z). Midl mRNA was increased three- to fivefold in all TSC mice, similar to the increase observed in the MT-COMP mice (Figure $4 \mathrm{Z}$ and 


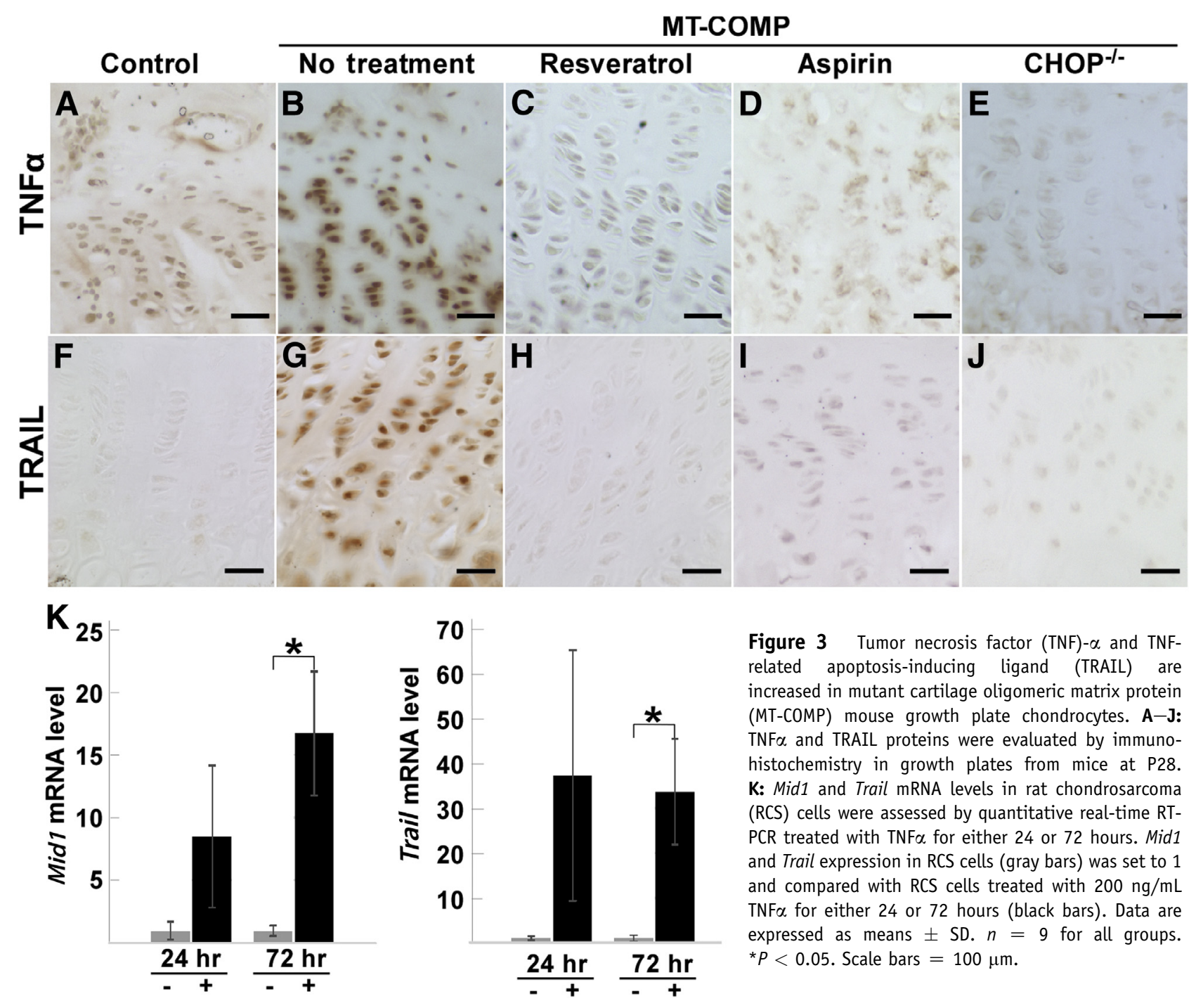

Figure 1A), linking Midl up-regulation with excessive mTORC1 signaling. 63

\section{mTORC1 Signaling and MT-COMP Growth Plate Pathology Is Reduced by Rapamycin Treatment}

Rapamycin treatment in MT-COMP mice decreased COMP intracellular retention and mTORC1 signaling, but not inflammatory markers (Figure 5, G-I). Rapamycin decreased mTORC1 signaling in the MT-COMP growth plates, as shown by the reduction in pS6 (Figure 5, A-C). Additionally, intracellular retention of COMP was decreased (Figure 5, D-F) and chondrocyte proliferation was increased in the MT-COMP mice (Figure 5, J-L). The inflammatory markers IL-16 and eosinophil peroxidase (data not shown) were not reduced in MT-COMP growth plates by rapamycin treatment (Figure 5). Similarly, rapamycin ameliorated the growth plate abnormalities in Tsc1-null mice by repressing mTORC1 signaling. ${ }^{63}$ In Tsc1-null mice, excessive mTORC1 results in short stature. ${ }^{63}$ MID1 was increased with MT-COMP expression, and mTORC1 signaling was stimulated directly by MID1 and indirectly through MID1 depletion of PP2A, an mTORC1 brake. These findings indicate that in the context of ER-stress growth plate pathology reducing mTORC1 signaling is therapeutic in mice.

Excessive mTORC1 Signaling Alters Levels of GLI2 and PTHrP, Which Modulate Murine Growth Plate Chondrocytes

Recent work has shown that mTORC1 regulates growth plate chondrocyte maturation. Ablation of the Tscl gene resulted in excessive mTORC1 signaling in mice, causing chondrodysplasia/dwarfing. ${ }^{63}$ mTORC1 regulated PTHrP, coordinating chondrocyte growth, proliferation, and differentiation/hypertrophy. ${ }^{63}$ This regulation occurred through the mTORC1 downstream S6 kinase- $\beta_{1}$ phosphorylation of GLI2, stimulating the transcription of PthrP. ${ }^{63}$ PTHrP controls bone development by regulating chondrocyte differentiation. To determine whether Gli2 and PTHrP are altered 


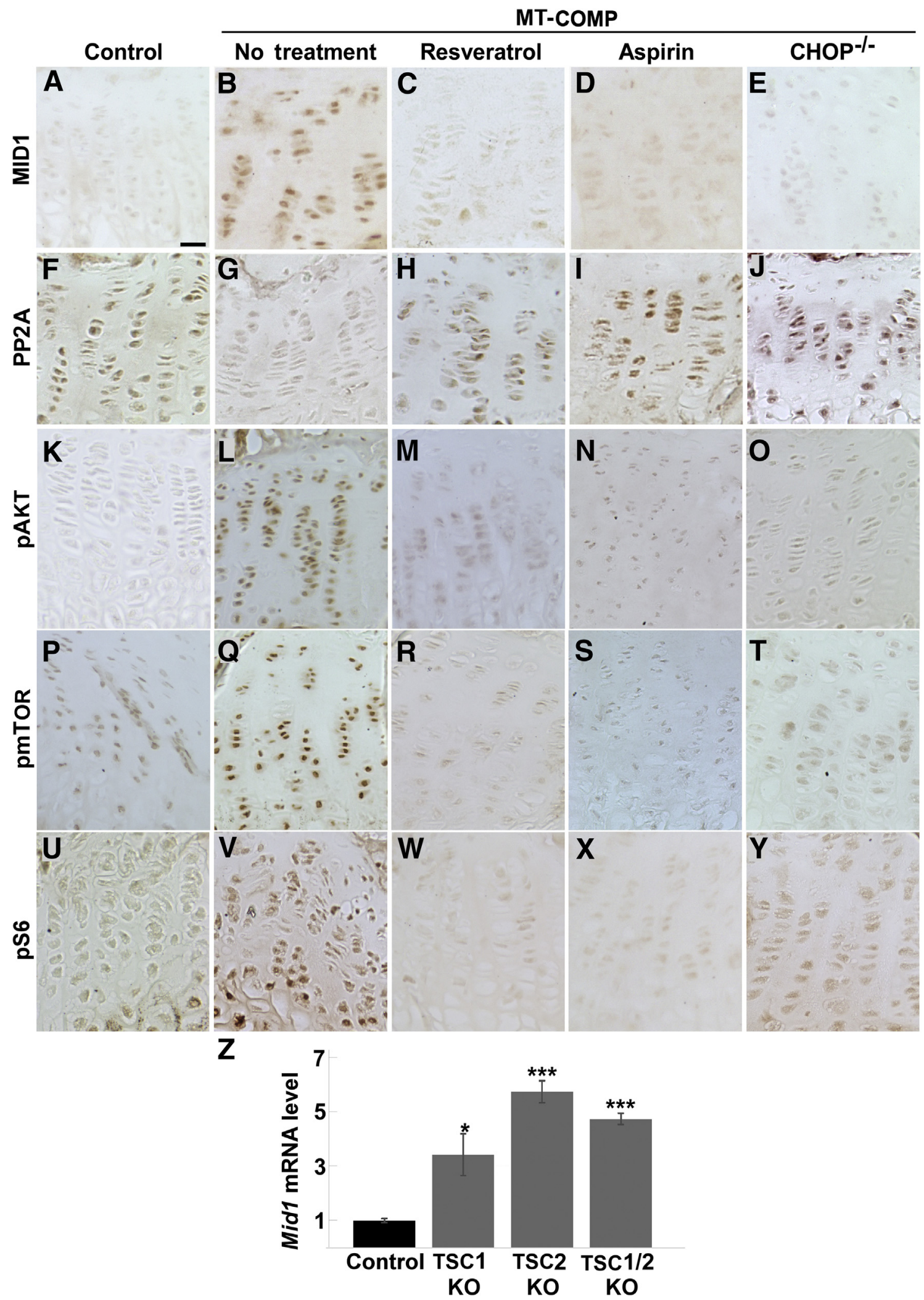

Figure 4 Increased midline 1 (MID1) decreases protein phosphatase (PP)-2a in mutant cartilage oligomeric matrix protein (MT-COMP) mouse growth plate chondrocytes. A-Y: MID1 (A-E), PP2A ( $\mathbf{F}-\mathbf{J})$, phosphorylated AKT $(\mathbf{K}-\mathbf{0})$, phosphorylated mammalian target of rapamycin (pmTOR; P-T), and phosphorylated $\mathrm{S} 6$ ribosomal protein ( $\mathrm{pS} 6 ; \mathbf{U}-\mathbf{Y}$ ) assessed by immunohistochemistry in P28 control (C57BL/6), MT-COMP with no treatment, MT-COMP treated with aspirin or resveratrol, and MT-COMP/CHOP $/-$ growth plate chondrocytes. AKT, mTOR, and pS6 are all components of the mTORC1 signaling pathway. Z: RTPCR performed on RNA extracted from tuberous sclerosis complex (TSC)-1-null, TSC2-null, TSC1/2-double null, and control mouse brains. Data are expressed as means \pm SD. $n>3(\mathbf{A}-\mathbf{Y}) ; n=3(\mathbf{Z}) .{ }^{*} P<0.05,{ }^{* *} P<0.0005$ versus control. Scale bar $=100 \mu \mathrm{m}$ (all images). 


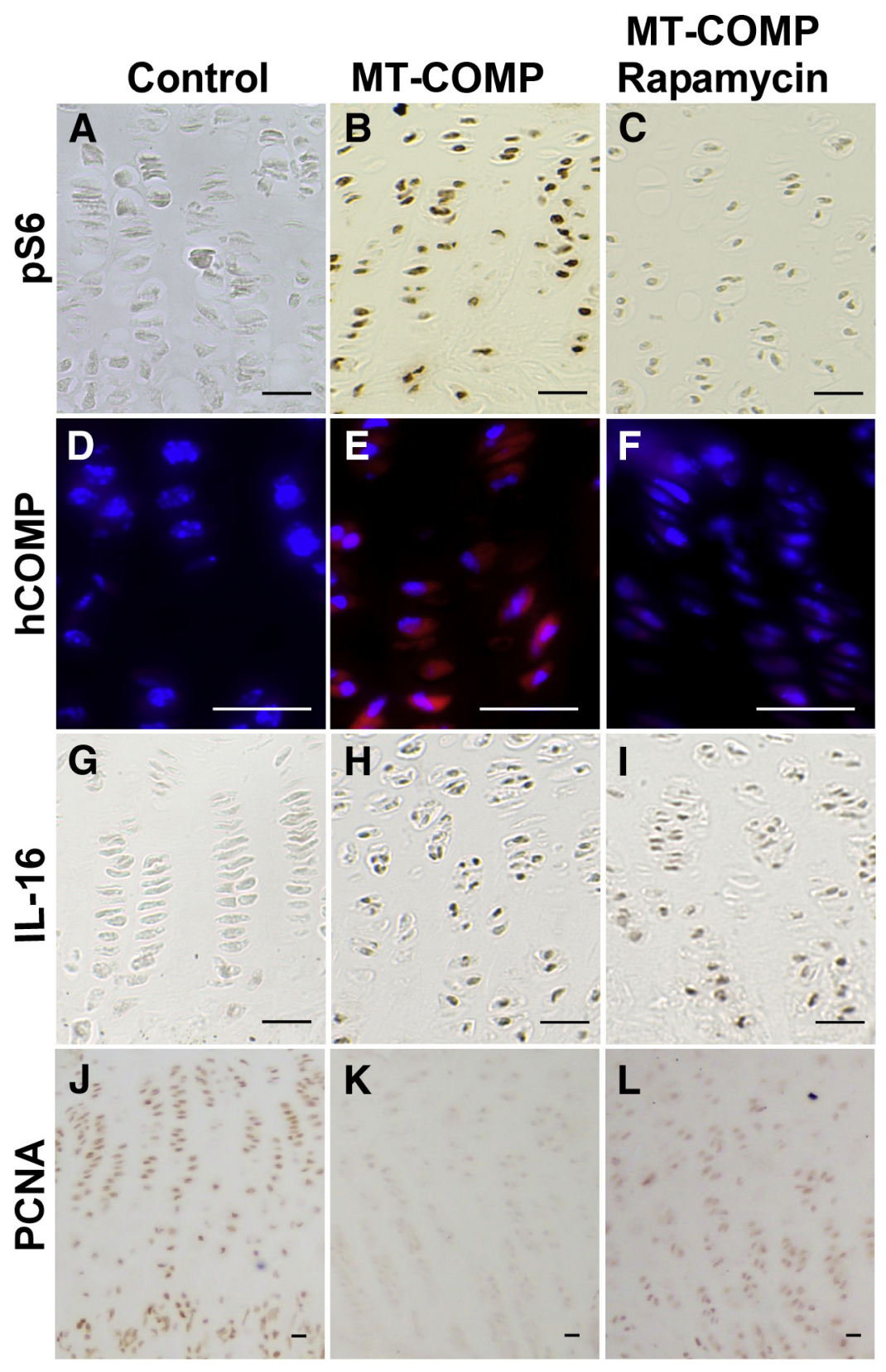

Figure 5 Rapamycin treatment of mutant cartilage oligomeric matrix protein (MT-COMP) mice decreases intracellular retention of COMP and mammalian target of rapamycin complex 1 (mTORC1) signaling but not inflammation. Control, untreated MT-COMP, and rapamycin-treated MT-COMP growth plates at P28 immunostained with antibodies for phosphorylated S6 ribosomal protein (pS6) $(\mathbf{A}-\mathbf{C})$, human (h) COMP (D-F), IL$16(\mathbf{G}-\mathbf{I})$, and DNA proliferation cell nuclear antigen (PCNA) (J-L). Rapamycin treatment reduces pS6 and intracellular COMP and improves chondrocyte proliferation. The inflammatory marker IL-16 is not reduced by rapamycin treatment. Scale bars $=100 \mu \mathrm{m}$.

in MT-COMP mice, growth plates were assessed at P28 in MT-COMP mice. pS6, a readout for mTORC1 signaling, was increased (Figure 5B). GLI2 and PTHrP expression levels were also increased, consistent with elevated mTORC1 signaling in MT-COMP growth plates compared to controls (Figure 6). This finding suggests that excessive mTORC1/GLI2/PTHrP stimulated by MT-COMP expression represses growth plate chondrocyte hypertrophy. ${ }^{64-66}$

\section{Anti-Inflammatory or Antioxidant Treatments or Elimination of CHOP-ER Stress Response Decreases Mid1 Expression}

Aspirin or resveratrol treatments have been reported to reduce intracellular accumulation of COMP, decrease inflammation markers and chondrocyte death, and increase proliferation and limb length. ${ }^{53}$ Additionally, the absence of CHOP, a key component of MT-COMP ER stress, in $\mathrm{MT}-\mathrm{COMP} / \mathrm{CHOP}^{-1-}$ mice was reported to have diminished the negative effects of MT-COMP expression. ${ }^{40,41}$ The expression levels of MID1 and PP2A in MT-COMP growth plates in mice treated with aspirin or resveratrol or loss of CHOP were next assessed. All of these therapeutic interventions restored normal levels of MID1 and PP2A in the growth plate (Figure 4, A-J), confirming that MID1 increases are related to MT-COMP chondrocyte pathology. Aspirin or resveratrol treatments or Chop gene ablation, all of which have been reported to dampen the MT-COMP chondrocyte pathology, ${ }^{53}$ also decreased the expression levels of TNF $\alpha$ and TRAIL, which drive increases in MID1 


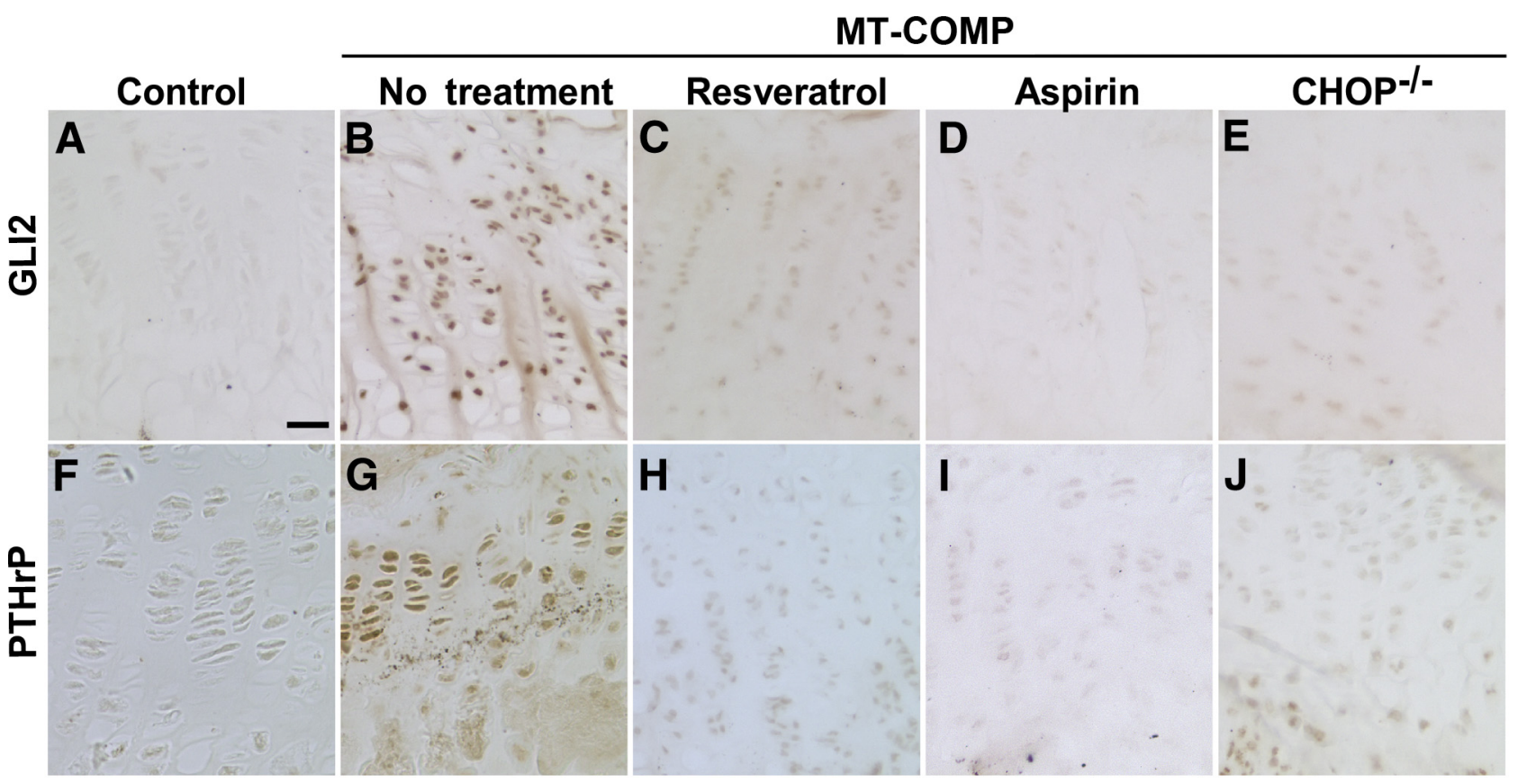

Figure 6 Glioma-associated oncogene homolog 2 (Gli2) and parathyroid hormone-related protein (PTHrP) are increased with mammalian target of rapamycin complex 1 (mTORC1) signaling in mutant cartilage oligomeric matrix protein (MT-COMP) growth plates. Control (C57BL/6), untreated MT-COMP, MTCOMP treated with resveratrol or aspirin, and $\mathrm{MT}-\mathrm{Comp} / \mathrm{CHOP}^{-/-}$growth plates from P28 mice were immunostained for phosphorylated GLI2 (A-E) and PTHrP $(\mathbf{F}-\mathbf{J})$. Scale bar $=100 \mu \mathrm{m}$ (all images). CHOP, CCAAT/enhancer-binding proteinehomologous protein.

(Figure 3, A-J). These treatments also normalized mTORC1 signaling (Figure 4), likely due to decreases in the PP2A level. Additionally, resveratrol or aspirin treatment or elimination of CHOP (MT-COMP/CHOP ${ }^{--}$) normalized GLI2 and PTHrP levels (Figure 6), also likely due to downregulation of mTORC1 signaling.

\section{Overexpression of MID1 Decreases Chop mRNA Levels} in the Presence of MT-COMP

To define the relationship between MID1 and CHOP, MID1 was overexpressed and knocked down in RSC cells expressing MT-COMP. Overexpression of MID1 in MT-COMP RCS cells (Figure 7A) was accompanied by decreased Chop mRNA levels (Figure 7B). MT-COMP expression has been associated with increases in Chop, growth arrest, and DNA damage-inducible proteins 34 and $45 \mathrm{a}$ and ER oxidoreductin protein $1 \beta$ mRNAs. ${ }^{40}$ siRNA knockdown of Midl in MT-COMP RCS cells resulted in increases in MT-COMP, Chop, Gadd34, Gadd45a, and Erolb (Figure 7, C-H).

\section{Discussion}

This is the first study linking ER stress to MID1/mTORC1 signaling in chondrocytes and other cell types, a finding that has significant implications for cellular functions including autophagy, protein synthesis, and potentially cellular viability. Moreover, these results identify new therapeutic targets for this pathologic process in a wide spectrum of ER-stress disorders. The pathologic mechanistic model shows that MT-COMP expression and ER retention stimulate unrelenting ER stress that initiates TNF $\alpha / T R A I L$ inflammation and MID1 up-regulation, resulting in increased mTORC1 signaling (Figure 8).

MT-COMP-induced chondrocyte death occurs through necroptosis (a form of cell death). ${ }^{40,41}$ This process begins with intracellular accumulation of MT-COMP, which induces ER stress and the unfolded protein response. The refolding and degradation branches of the unfolded protein response are not fully engaged by MT-COMP retention, and only the protein kinase RNA-activated-like endoplasmic reticulum kinase/CHOP branch proceeds beyond initial activation. ${ }^{40}$ Reactive oxygen species are generated by CHOP/ERO1 $\beta$ along with NADPH oxidase 4 , creating DNA damage and the release of phosphorylated histone $2 \mathrm{AX}^{40}$ MT-COMP-induced mitochondrial dysfunction stimulates the release of cell death-inducing factor and its translocation to the nucleus, where it interacts with phosphorylated histone 2AX, inducing necroptosis. ${ }^{40,41} \mathrm{MID}$, a microtubule stabilizer, which was increased, may be activated to sustain chondrocyte viability in this pathologic process. ${ }^{47,67}$ The ER is inextricably linked to microtubules, as microtubules are the transport highways used by the ER to export its cargo. ${ }^{68}$ Persistent ER stress is known to stabilize the microtubule network, thereby providing resistance to apoptosis. ${ }^{69-77}$ Additionally, in our study, the 

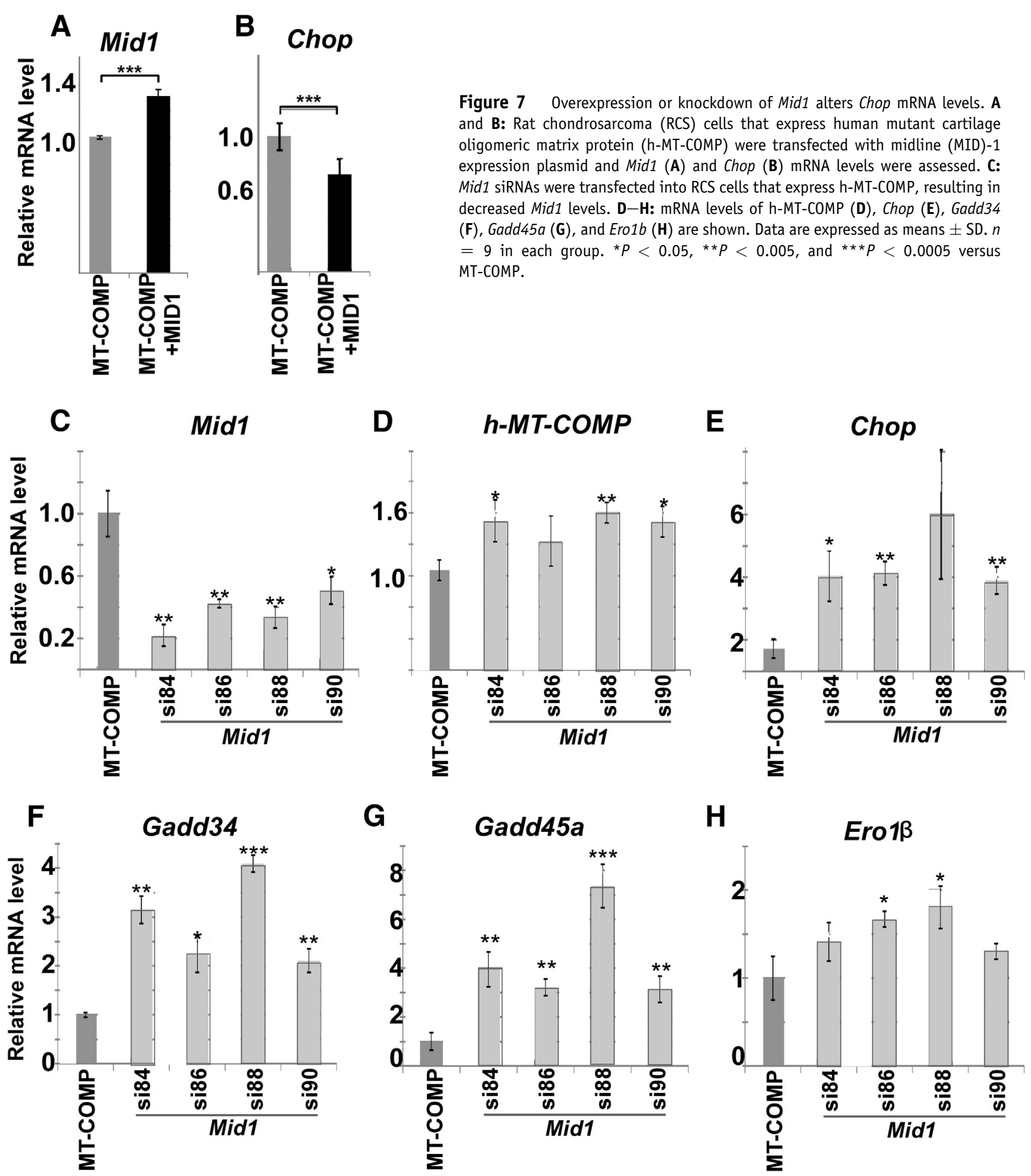

G

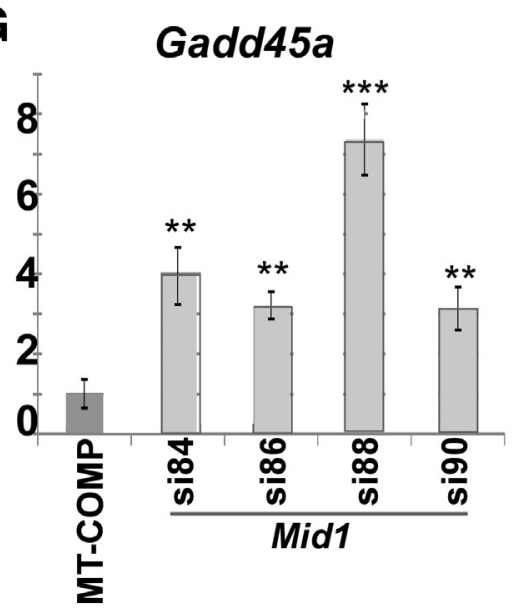

H

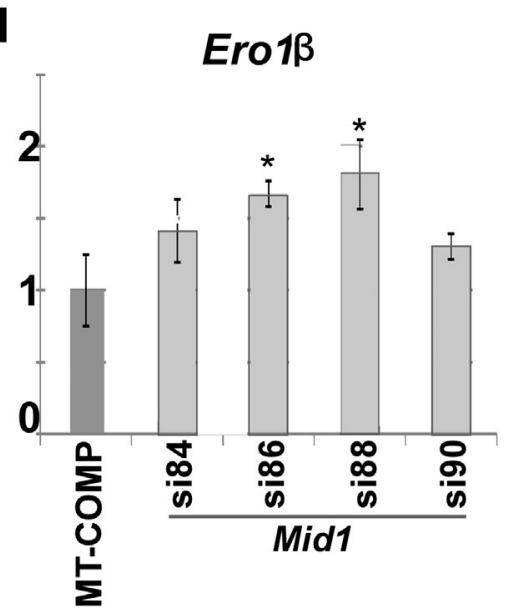

overexpression of MID1 was associated with a decrease in Chop, whereas knockdown of Mid1 was associated with an increase in the stress-related transcripts Chop, Gadd34, Gadd45a, and Erolb. It is not clear whether the increase in Chop when MID1 was knocked down was due to decreased Midl or increased MT-COMP. MID1 increases stability and translational efficiency of select mRNAs through MID1associated sequence. ${ }^{62}$ However, COMP mRNA does not contain a MID1-binding domain, and the inverse relationship between MID1 and MT-COMP suggests that MID1 does not directly regulate COMP mRNA levels. Based on this information, increased MID1 in ER stress-related 

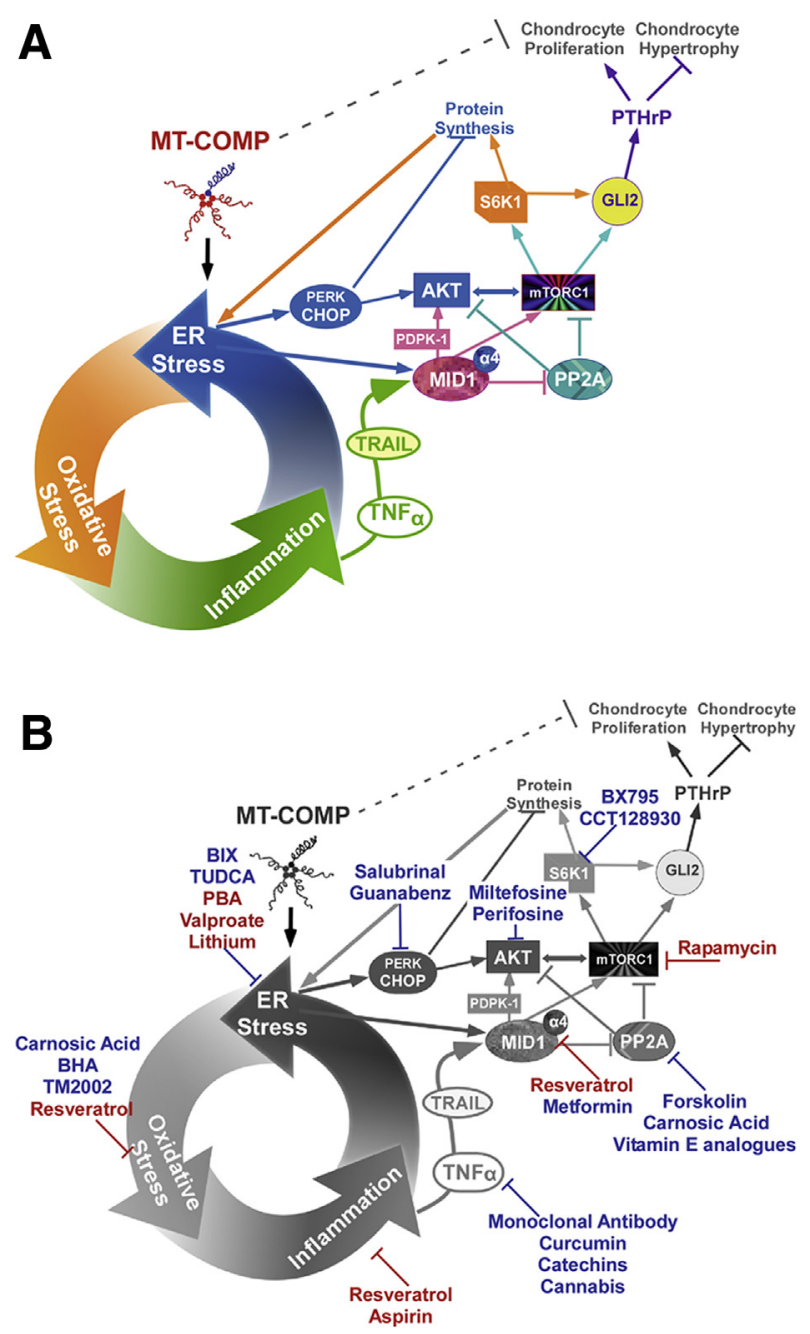

Figure 8 Model depicting the roles of midline 1 (MID1), mammalian target of rapamycin, complex 1 (mTORC1), and parathyroid hormonerelated protein (PTHrP) in mutant cartilage oligomeric matrix protein (MT-COMP) chondrocyte pathology. A: MT-COMP expression elicits endoplasmic reticulum (ER) stress through PERK/CHOP, which leads to oxidative stress and inflammation. The inflammatory process driven in part by tumor necrosis factor (TNF)- $\alpha$ increases TNF-related apoptosisinducing ligand (TRAIL) and MID1. CHOP down-regulates general protein synthesis as part of the unfolded protein response and upregulates AKT. AKT and MID1 stimulate mTORC1 signaling, along with a decrease in the mTORC1 brake, protein phosphatase (PP)-2A. mTORC1 signaling drives protein synthesis through protein $\mathrm{S} 6$ kinase/phosphoS6 and likely generates additional ER stress. mTORC1 up-regulates glioma-associated oncogene homolog 2 (zinc finger protein) (GLI)-2 and PTHrP, which alters chondrocyte proliferation and hypertrophy. B: Resveratrol counteracts several processes involved in the MT-COMP chondrocyte pathology including oxidative stress, inflammation, and $M I D 1 / \alpha_{4}$ complex. Aspirin, a cyclooxygenase-2 inhibitor, dampens inflammation and diminishes the negative effects of MT-COMP expression (red). Rapamycin decreases intracellular retention of MTCOMP and mTORC1 signaling but does not improve inflammation and proliferation. Other drugs to potentially reduce the MT-COMP chondrocyte pathology are shown in blue. BHA, butylated hydroxyanisole; $\mathrm{BIX}$, immunoglobulin heavy-chain-binding protein inducer $\mathrm{X}$; $\mathrm{CHOP}$, CCAAT/enhancer-binding protein-homologous protein; PBA, 4phenylbutyrate; PDPK-1, protein 3-phosphoinositide-dependent protein kinase-1; PERK, protein kinase RNA-activated-like endoplasmic reticulum kinase TUDCA, tauroursodeoxycholic acid. conditions likely slows but does not ultimately eliminate chondrocyte death. $2,33,36,38,40,66,78$

It has been tested whether MID1/mTORC1 signaling is involved in other ER stress-related conditions, including Alzheimer, Huntington, and Parkinson diseases; amyotrophic lateral sclerosis; cancer; type II diabetes ${ }^{79}$; and TSC. ${ }^{58}$ Both PSACH and Alzheimer disease involve protein misfolding, oxidative stress, inflammation, and premature cell death. ${ }^{36,41,80-87}$ MID1 is elevated in Alzheimerdiseased brains compared to healthy controls. ${ }^{88}$ Consistent with these findings, mTORC1 is increased and PP2A, which is negatively regulated by MID1, is decreased in Alzheimer disease. $^{89}$ Furthermore, in human TSC or mice lacking either Tsc1 or Tsc 2 or both Tsc genes, unrestrained mTOR signaling generates ER stress with a concurrent increase in mTOR activation. ${ }^{90}$ Midl mRNA was increased in the brain tissue of Tsc1-, Tsc2-, and Tsc1/2-double null mice, providing further evidence that MID1/mTORC1 is linked to ER stress (Figure 4Z). Moreover, dampening mTORC1 signaling was reported to improve Parkinson disease outcomes in mice, preventing the development of dyskinesia. ${ }^{91}$ All together, these combined observations establish that upregulation of MID1 accompanies elevated mTORC1 signaling in a variety of ER stress-related conditions. ${ }^{92}$

mTORC1 is a master regulator of growth in response to nutritional status, energy levels, cellular stress, growth factors, and amino acids, and regulates general protein translation and autophagy. ${ }^{93}$ Dysfunction of secretory cells or misfolded proteins (chondrocytes, $\beta$-islet cells, and neurons) are a significant cause of ER stress-related conditions. Secretory cells synthesize large amounts of exported proteins that are necessary for organ/tissue functioning. Since mTORC1 regulates general protein synthesis, increases in mTORC1 signaling may sustain protein synthesis during periods of ER stress, allowing cells to continue functioning. During ER stress, the unfolded protein response down-regulates general translation to allow clearance of misfolded protein(s). In contrast, mTORC1 stimulates general protein synthesis, which may ultimately exacerbate ER stress and inhibit ER clearance. Additionally, increased mTORC1 signaling represses autophagy, eliminating another mechanism to clear misfolded proteins and resolve ER stress. Collectively, these results indicate that increased MID1 during ER stress functions to prolong cellular survival as well as stimulates excess mTORC1 signaling, which ultimately may be detrimental.

Besides playing a role in ER stress-related disorders, mTORC1 signaling regulates PTHrP and GLI2 modulation of chondrocyte hypertrophy, and increased mTORC1 signaling is associated with osteoarthritis joint degeneration. ${ }^{94}$ In the present study, PTHrP and GL12 were both increased in growth plate chondrocytes in MT-COMP mice (Figure 6). This finding suggests that the lack of hypertrophic chondrocytes in the PSACH growth plate and the early-onset osteoarthritis in PSACH are additional consequences of increased mTORC1 signaling. 
This work identifies the mTORC1 pathway as a potential therapeutic target in ER-stress conditions. It has been reported that aspirin and resveratrol treatments dampen MTCOMP chondrocyte pathology by reducing inflammation and oxidative stress. ${ }^{53}$ In the present study, these treatments also reduced Mid1, TNF $\alpha$, Trail, and mTORC1 signaling in mice. Although rapamycin targeting of mTORC1 in the MT-COMP mouse decreased pS6 and MT-COMP intracellular accumulation, and increased DNA proliferation, it did not reduce inflammation (eosinophil peroxidase or IL16). This is an expected result since MID1 up-regulation is downstream of TNF $\alpha /$ TRAIL inflammation and therefore rapamycin may be more effective when used in combination with anti-inflammatory medications such as aspirin. However, there are significant side effects (suppression of the immune system, increased risks for infections and cancer, and impaired wound healing) with chronic rapamycin treatments that may limit their current therapeutic utility (Food and Drug Administration, https://www.accessdata.fda. gov/drugsatfda_docs/label/2010/021110s058lbl.pdf, last accessed September, 17, 2018).

Given the numerous conditions that involve ER dysfunction, a complete understanding all of the consequences of ER stress is crucial for the development of mechanism-driven therapeutic approaches. The results of this work show that TNF $\alpha$ inflammation, MID1, mTORC1 signaling, the microtubule network, protein synthesis, and autophagy form a complex, multifaceted response to protein accumulation in the ER when the clearance efforts fail, and MID1 may act as a prosurvival factor to extend chondrocyte life. Importantly, therapeutics interrupting the upstream selfperpetuating pathologic loop between ER stress, inflammation, and oxidative stress may be most effective.

\section{Acknowledgments}

We thank Frankie Chiu for technical assistance, and Dr. Makoto Suzuki for providing the MID1-overexpression plasmid.

K.L.P. designed the study, analyzed the data, performed literature search, generated the figures, and wrote the manuscript; F.C., A.C.V., and M.G.H. collected and analyzed data; M.J.G. collected data and reviewed the manuscript; J.T.H. designed the study, interpreted data, and wrote the manuscript.

\section{Supplemental Data}

Supplemental material for this article can be found at https://doi.org/10.1016/j.ajpath.2018.09.008.

\section{References}

1. DiCesare PE, Morgelin M, Mann K, Paulsson M: Cartilage oligomeric matrix protein and thrombospondin 1. Purification from articular cartilage, electron microscopic structure, and chondrocyte binding. Eur J Biochem 1994, 223:927-937

2. Hecht JT, Deere M, Putnam E, Cole W, Vertel B, Chen H, Lawler J: Characterization of cartilage oligomeric matrix protein (COMP) in human normal and pseudoachondroplasia musculoskeletal tissues. Matrix Biol 1998, 17:269-278

3. Hedbom E, Antonsson P, Hjerpe A, Aeschlimann D, Paulsson M, Rosa-Pimentel E, Sommarin Y, Wendel M, Oldberg A, Heinegard D: Cartilage matrix proteins. An acidic oligomeric protein (COMP) detected only in cartilage. J Biol Chem 1992 , 267:6132-6136

4. Urban JP, Maroudas A, Bayliss MT, Dillon J: Swelling pressures of proteoglycans at the concentrations found in cartilaginous tissues. Biorheology 1979, 16:447-464

5. Kempson GE, Freeman MA, Swanson SA: Tensile properties of articular cartilage. Nature 1968, 220:1127-1128

6. Schmidt MB, Mow VC, Chun LE, Eyre DR: Effects of proteoglycan extraction on the tensile behavior of articular cartilage. J Orthop Res 1990, 8:353-363

7. Adams JC, Tucker RP, Lawler J: The Thrombospondin Gene Family. Austin, TX, R.G. Landes Co., 1995

8. Holden P, Meadows RS, Chapman KL, Grant ME, Kadler KE, Briggs MD: Cartilage oligomeric matrix protein interacts with type IX collagen, and disruptions to these interactions identify a pathogenetic mechanism in a bone dysplasia family. J Biol Chem 2001, 276:6046-6055

9. Mann HH, Ozbek S, Engel J, Paulsson M, Wagener R: Interactions between the cartilage oligomeric matrix protein and matrilins. Implications for matrix assembly and the pathogenesis of chondrodysplasias. J Biol Chem 2004, 279:25294-25298

10. Thur J, Rosenberg K, Nitsche DP, Pihlajamaa T, Ala-Kokko L, Heinegard D, Paulsson M, Maurer P: Mutations in cartilage oligomeric matrix protein causing pseudoachondroplasia and multiple epiphyseal dysplasia affect binding of calcium and collagen I, II, and IX. J Biol Chem 2001, 276:6083-6092

11. Rosenberg K, Olsson H, Morgelin M, Heinegard D: Cartilage oligomeric matrix protein shows high affinity zinc-dependent interaction with triple helical collagen. J Biol Chem 1998, 273: 20397-20403

12. Kipnes J, Carlberg AL, Loredo GA, Lawler J, Tuan RS, Hall DJ: Effect of cartilage oligomeric matrix protein on mesenchymal chondrogenesis in vitro. Osteoarthritis Cartilage 2003, 11:442-454

13. Xu K, Zhang Y, Ilalov K, Carlson CS, Feng JQ, Di Cesare PE, Liu CJ: Cartilage oligomeric matrix protein associates with granulin-epithelin precursor (GEP) and potentiates GEPstimulated chondrocyte proliferation. J Biol Chem 2007, 282: 11347-11355

14. Chen FH, Thomas AO, Hecht JT, Goldring MB, Lawler J: Cartilage oligomeric matrix protein/thrombospondin 5 supports chondrocyte attachment through interaction with integrins. J Biol Chem 2005, 280: 32655-32661

15. Briggs MD, Chapman KL: Pseudoachondroplasia and multiple epiphyseal dysplasia: mutation review, molecular interactions, and genotype to phenotype correlations. Hum Mutat 2002, 19: 465-478

16. Briggs MD, Hoffman SM, King LM, Olsen AS, Mohrenweiser H, Leroy JG, Mortier GR, Rimoin DL, Lachman RS, Gaines ES: Pseudoachondroplasia and multiple epiphyseal dysplasia due to mutations in the cartilage oligomeric matrix protein gene. Nat Genet 1995, 10:330-336

17. Briggs MD, Mortier GR, Cole WG, King LM, Golik SS, Bonaventure J, Nuytinck L, De Paepe A, Leroy JG, Biesecker L, Lipson M, Wilcox WR, Lachman RS, Rimoin DL, Knowlton RG, Cohn DH: Diverse mutations in the gene for cartilage oligomeric matrix protein in the pseudoachondroplasiamultiple epiphyseal dysplasia disease spectrum. Am J Hum Genet 1998, 62:311-319 
18. Chen H, Deere M, Hecht JT, Lawler J: Cartilage oligomeric matrix protein is a calcium-binding protein, and a mutation in its type 3 repeats causes conformational changes. J Biol Chem 2000, 275 : 26538-26544

19. Chen TL, Stevens JW, Cole WG, Hecht JT, Vertel BM: Cell-type specific trafficking of expressed mutant COMP in a cell culture model for PSACH. Matrix Biol 2004, 23:433-444

20. Cooper RR, Ponseti IV, Maynard JA: Pseudoachondroplastic dwarfism. A rough-surfaced endoplasmic reticulum storage disorder. J Bone Joint Surg Am 1973, 55:475-484

21. Delot E, Brodie SG, King LM, Wilcox WR, Cohn DH: Physiological and pathological secretion of cartilage oligomeric matrix protein by cells in culture. J Biol Chem 1998, 273:26692-26697

22. DiCesare PE, Morgelin M, Carlson CS, Pasumarti S, Paulsson M: Cartilage oligomeric matrix protein: isolation and characterization from human articular cartilage. J Orthop Res 1995, 13:422-428

23. Dinser R, Zaucke F, Kreppel F, Hultenby K, Kochanek S, Paulsson M, Maurer P: Pseudoachondroplasia is caused through both intra- and extracellular pathogenic pathways. J Clin Invest 2002, 110: $505-513$

24. Duke J, Montufar-Solis D, Underwood S, Lalani Z, Hecht JT: Apoptosis staining in cultured pseudoachondroplasia chondrocytes. Apoptosis 2003, 8:191-197

25. Ikegawa S, Ohashi H, Nishimura G, Kim KC, Sannohe A, Kimizuka M, Fukushima Y, Nagai T, Nakamura Y: Novel and recurrent COMP (cartilage oligomeric matrix protein) mutations in pseudoachondroplasia and multiple epiphyseal dysplasia. Hum Genet 1998, 103:633-638

26. Kleerekoper Q, Hecht JT, Putkey JA: Disease-causing mutations in cartilage oligomeric matrix protein cause an unstructured $\mathrm{Ca} 2+$ binding domain. J Biol Chem 2002, 277:10581-10589

27. Maddox BK, Mokashi A, Keene DR, Bachinger HP: A cartilage oligomeric matrix protein mutation associated with pseudoachondroplasia changes the structural and functional properties of the type 3 domain. J Biol Chem 2000, 275:11412-11417

28. McKeand J, Rotta J, Hecht JT: Natural history study of pseudoachondroplasia. Am J Med Genet 1996, 63:406-410

29. Merritt TM, Alcorn JL, Haynes R, Hecht JT: Expression of mutant cartilage oligomeric matrix protein in human chondrocytes induces the pseudoachondroplasia phenotype. J Orthop Res 2006, 24: 700-707

30. Merritt TM, Bick R, Poindexter BJ, Alcorn JL, Hecht JT: Unique matrix structure in the rough endoplasmic reticulum cisternae of pseudoachondroplasia chondrocytes. Am J Pathol 2007, 170: 293-300

31. Unger S, Hecht JT: Pseudoachondroplasia and multiple epiphyseal dysplasia: new etiologic developments. Am J Med Genet 2001, 106: 244

32. Hecht JT, Montufar-Solis D, Decker G, Lawler J, Daniels K, Duke PJ: Retention of cartilage oligomeric matrix protein (COMP) and cell death in redifferentiated pseudoachondroplasia chondrocytes. Matrix Biol 1998, 17:625-633

33. Hecht JT, Hayes E, Haynes R, Cole WG: COMP mutations, chondrocyte function and cartilage matrix. Matrix Biol 2005, 23:525-533

34. Hecht JT, Hayes E, Snuggs M, Decker G, Montufar-Solis D, Doege K, Mwalle F, Poole R, Stevens J, Duke PJ: Calreticulin, PDI, Grp94 and BiP chaperone proteins are associated with retained COMP in pseudoachondroplasia chondrocytes. Matrix Biol 2001, 20: $251-262$

35. Hecht JT, Nelson LD, Crowder E, Wang Y, Elder FF, Harrison WR, Francomano CA, Prange CK, Lennon GG, Deere M, Lawler J: Mutations in exon 17B of cartilage oligomeric matrix protein (COMP) cause pseudoachondroplasia. Nat Genet 1995, 10: 325-329

36. Posey KL, Hayes E, Haynes R, Hecht JT: Role of TSP-5/COMP in pseudoachondroplasia. Int J Biochem Cell Biol 2004, 36:1005-1012
37. Posey KL, Hecht JT: Novel therapeutic interventions for pseudoachondroplasia. Bone 2017, 102:60-68

38. Posey KL, Veerisetty AC, Liu P, Wang HR, Poindexter BJ, Bick R, Alcorn JL, Hecht JT: An inducible cartilage oligomeric matrix protein mouse model recapitulates human pseudoachondroplasia phenotype. Am J Pathol 2009, 175:1555-1563

39. Posey KL, Coustry F, Veerisetty AC, Hossain M, Gattis D, Booten S, Alcorn JL, Seth PP, Hecht JT: Antisense reduction of mutant COMP reduces growth plate chondrocyte pathology. Mol Ther 2017, 25: $705-714$

40. Coustry F, Posey KL, Liu P, Alcorn JL, Hecht JT: D469del-COMP retention in chondrocytes stimulates caspase-independent necroptosis. Am J Pathol 2012, 180:738-748

41. Posey KL, Coustry F, Veerisetty AC, Liu P, Alcorn JL, Hecht JT: Chop (Ddit3) is essential for D469del-COMP retention and cell death in chondrocytes in an inducible transgenic mouse model of pseudoachondroplasia. Am J Pathol 2012, 180:727-737

42. Posey KL, Coustry F, Veerisetty AC, Liu P, Alcorn JL, Hecht JT: Chondrocyte-specific pathology during skeletal growth and therapeutics in a murine model of pseudoachondroplasia. J Bone Miner Res 2014, 29:1258-1268

43. Short KM, Hopwood B, Yi Z, Cox TC: MID1 and MID2 homo- and heterodimerise to tether the rapamycin-sensitive $\mathrm{PP} 2 \mathrm{~A}$ regulatory subunit, alpha 4, to microtubules: implications for the clinical variability of X-linked Opitz GBBB syndrome and other developmental disorders. BMC Cell Biol 2002, 3:1

44. Jiang CC, Yang F, Thorne RF, Zhu BK, Hersey P, Zhang XD: Human melanoma cells under endoplasmic reticulum stress acquire resistance to microtubule-targeting drugs through XBP-1-mediated activation of Akt. Neoplasia 2009, 11:436-447

45. Placido AI, Pereira CM, Correira SC, Carvalho C, Oliveira CR, Moreira PI: Phosphatase 2A inhibition affects endoplasmic reticulum and mitochondria homeostasis via cytoskeletal alterations in brain endothelial cells. Mol Neurobiol 2017, 54:154-168

46. Marciniak SJ, Yun CY, Oyadomari S, Novoa I, Zhang Y, Jungreis R, Nagata K, Harding HP, Ron D: CHOP induces death by promoting protein synthesis and oxidation in the stressed endoplasmic reticulum. Genes Dev 2004, 18:3066-3077

47. Suzuki M, Hara Y, Takagi C, Yamamoto TS, Ueno N: MID1 and MID2 are required for Xenopus neural tube closure through the regulation of microtubule organization. Development 2010, 137: 2329-2339

48. Hecht JT, Sage EH: Retention of the matricellular protein SPARC in the endoplasmic reticulum of chondrocytes from patients with pseudoachondroplasia. J Histochem Cytochem 2006, 54:269-274

49. Parker AL, Kavallaris M, McCarroll JA: Microtubules and their role in cellular stress in cancer. Front Oncol 2014, 4:153

50. King KB, Kimura JH: The establishment and characterization of an immortal cell line with a stable chondrocytic phenotype. J Cell Biochem 2003, 89:992-1004

51. Oslowski CM, Urano F: Measuring ER stress and the unfolded protein response using mammalian tissue culture system. Methods Enzymol 2011, 490:71-92

52. Radi R: Peroxynitrite, a stealthy biological oxidant. J Biol Chem 2013, 288:26464-26472

53. Posey KL, Coustry F, Veerisetty AC, Hossain M, Alcorn JL, Hecht JT: Antioxidant and anti-inflammatory agents mitigate pathology in a mouse model of pseudoachondroplasia. Hum Mol Genet 2015, 24:3918-3928

54. Collison A, Hatchwell L, Verrills N, Wark PA, de Siqueira AP, Tooze M, Carpenter H, Don AS, Morris JC, Zimmermann N, Bartlett NW, Rothenberg ME, Johnston SL, Foster PS, Mattes J: The E3 ubiquitin ligase midline 1 promotes allergen and rhinovirusinduced asthma by inhibiting protein phosphatase $2 \mathrm{~A}$ activity. Nat Med 2013, 19:232-237

55. Collison AM, Sokulsky LA, Sherrill JD, Nightingale S, Hatchwell L, Talley NJ, Walker MM, Rothenberg ME, Mattes J: TNF-related 
apoptosis-inducing ligand (TRAIL) regulates midline-1, thymic stromal lymphopoietin, inflammation, and remodeling in experimental eosinophilic esophagitis. J Allergy Clin Immunol 2015, 136: 971-982

56. Trockenbacher A, Suckow V, Foerster J, Winter J, Krauss S, Ropers HH, Schneider R, Schweiger S: MID1, mutated in Opitz syndrome, encodes an ubiquitin ligase that targets phosphatase $2 \mathrm{~A}$ for degradation. Nat Genet 2001, 29:287-294

57. Liu J, Prickett TD, Elliott E, Meroni G, Brautigan DL: Phosphorylation and microtubule association of the Opitz syndrome protein mid-1 is regulated by protein phosphatase $2 \mathrm{~A}$ via binding to the regulatory subunit alpha 4. Proc Natl Acad Sci U S A 2001, 98: $6650-6655$

58. Reith RM, Way S, McKenna J 3rd, Haines K, Gambello MJ: Loss of the tuberous sclerosis complex protein tuberin causes Purkinje cell degeneration. Neurobiol Dis 2011, 43:113-122

59. Ozcan U, Ozcan L, Yilmaz E, Duvel K, Sahin M, Manning BD, Hotamisligil GS: Loss of the tuberous sclerosis complex tumor suppressors triggers the unfolded protein response to regulate insulin signaling and apoptosis. Mol Cell 2008, 29: $541-551$

60. Liu E, Knutzen CA, Krauss S, Schweiger S, Chiang GG: Control of mTORC1 signaling by the Opitz syndrome protein MID1. Proc Natl Acad Sci U S A 2011, 108:8680-8685

61. Iwenofu OH, Lackman RD, Staddon AP, Goodwin DG, Haupt HM, Brooks JS: Phospho-S6 ribosomal protein: a potential new predictive sarcoma marker for targeted mTOR therapy. Mod Pathol 2008, 21: $231-237$

62. Aranda-Orgilles B, Rutschow D, Zeller R, Karagiannidis AI, Kohler A, Chen C, Wilson T, Krause S, Roepcke S, Lilley D, Schneider R, Schweiger S: Protein phosphatase 2A (PP2A)-specific ubiquitin ligase MID1 is a sequence-dependent regulator of translation efficiency controlling 3-phosphoinositide-dependent protein kinase-1 (PDPK-1). J Biol Chem 2011, 286:39945-39957

63. Yan B, Zhang Z, Jin D, Cai C, Jia C, Liu W, Wang T, Li S, Zhang H, Huang B, Lai P, Wang H, Liu A, Zeng C, Cai D, Jiang Y, Bai X: mTORC1 regulates PTHrP to coordinate chondrocyte growth, proliferation and differentiation. Nat Commun 2016, 7:11151

64. Lindseth RE, Danigelis JA, Murray DG, Wray JB: Spondylo-epiphyseal dysplasia (pseudoachondroplastic type). Case report with pathologic and metabolic investigations. Am J Dis Child 1967, 113: $721-726$

65. Stanescu V, Stanescu R, Maroteaux P: Pathogenic mechanisms in osteochondrodysplasias. J Bone Joint Surg Am 1984, 66: $817-836$

66. Hecht JT, Makitie O, Hayes E, Haynes R, Susic M, MontufarSolis D, Duke PJ, Cole WG: Chondrocyte cell death and intracellular distribution of COMP and type IX collagen in the pseudoachondroplasia growth plate. J Orthop Res 2004, 22:759-767

67. Schweiger S, Foerster J, Lehmann T, Suckow V, Muller YA, Walter G, Davies T, Porter H, van Bokhoven H, Lunt PW, Traub P, Ropers HH: The Opitz syndrome gene product, MID1, associates with microtubules. Proc Natl Acad Sci U S A 1999, 96:2794-2799

68. Palmer KJ, Watson P, Stephens DJ: The role of microtubules in transport between the endoplasmic reticulum and Golgi apparatus in mammalian cells. Biochem Soc Symp 2005, 72:1-13

69. Gately DP, Howell SB: Paclitaxel activation of the GADD153 promoter through a cellular injury response element containing an essential Sp1 binding site. J Biol Chem 1996, 271: 20588-20593

70. Seyb KI, Ansar S, Bean J, Michaelis ML: beta-Amyloid and endoplasmic reticulum stress responses in primary neurons: effects of drugs that interact with the cytoskeleton. J Mol Neurosci 2006, 28 : $111-123$

71. Gately DP, Sharma A, Christen RD, Howell SB: Cisplatin and taxol activate different signal pathways regulating cellular injury-induced expression of GADD153. Br J Cancer 1996, 73:18-23
72. Jiang P, Gan M, Ebrahim AS, Lin WL, Melrose HL, Yen SH: ER stress response plays an important role in aggregation of alpha-synuclein. Mol Neurodegener 2010, 5:56

73. Kim R, Ohi Y, Inoue H, Aogi K, Toge T: Introduction of gadd153 gene into gastric cancer cells can modulate sensitivity to anticancer agents in association with apoptosis. Anticancer Res 1999, 19: $1779-1783$

74. Stockwell SR, Platt G, Barrie SE, Zoumpoulidou G, Te Poele RH, Aherne GW, Wilson SC, Sheldrake P, McDonald E, Venet M, Soudy C, Elustondo F, Rigoreau L, Blagg J, Workman P, Garrett MD, Mittnacht S: Mechanism-based screen for G1/S checkpoint activators identifies a selective activator of EIF2AK3/PERK signalling. PLoS One 2012, 7:e28568

75. Swanton C, Marani M, Pardo O, Warne PH, Kelly G, Sahai E, Elustondo F, Chang J, Temple J, Ahmed AA, Brenton JD, Downward J, Nicke B: Regulators of mitotic arrest and ceramide metabolism are determinants of sensitivity to paclitaxel and other chemotherapeutic drugs. Cancer Cell 2007, 11:498-512

76. Wu Y, Fabritius M, Ip C: Chemotherapeutic sensitization by endoplasmic reticulum stress: increasing the efficacy of taxane against prostate cancer. Cancer Biol Ther 2009, 8:146-152

77. Ho CT, Chang YJ, Yang LX, Wei PL, Liu TZ, Liu JJ: A novel microtubule-disrupting agent induces endoplasmic reticular stressmediated cell death in human hepatocellular carcinoma cells. PLoS One 2015, 10:e136340

78. Posey KL, Alcorn JL, Hecht JT: Pseudoachondroplasia/COMP translating from the bench to the bedside. Matrix Biol 2014, 37: $167-173$

79. Schonthal AH: Endoplasmic reticulum stress: its role in disease and novel prospects for therapy. Scientifica (Cairo) 2012, 2012: 857516

80. Posey KL, Hecht JT: The role of cartilage oligomeric matrix protein (COMP) in skeletal disease. Curr Drug Targets 2008, 9 869-877

81. Greig NH, Mattson MP, Perry $\mathrm{T}$, Chan SL, Giordano T, Sambamurti K, Rogers JT, Ovadia H, Lahiri DK: New therapeutic strategies and drug candidates for neurodegenerative diseases: p53 and TNF-alpha inhibitors, and GLP-1 receptor agonists. Ann N Y Acad Sci 2004, 1035:290-315

82. Yankner BA, Duffy LK, Kirschner DA: Neurotrophic and neurotoxic effects of amyloid beta protein: reversal by tachykinin neuropeptides. Science 1990, 250:279-282

83. Hernandez F, Avila J: Tauopathies. Cell Mol Life Sci 2007, 64 2219-2233

84. Hashimoto M, Rockenstein E, Crews L, Masliah E: Role of protein aggregation in mitochondrial dysfunction and neurodegeneration in Alzheimer's and Parkinson's diseases. Neuromolecular Med 2003, 4: $21-36$

85. Su B, Wang X, Nunomura A, Moreira PI, Lee HG, Perry G, Smith MA, Zhu X: Oxidative stress signaling in Alzheimer's disease. Curr Alzheimer Res 2008, 5:525-532

86. Iqbal K, Alonso Adel C, Chen S, Chohan MO, El-Akkad E, Gong CX, Khatoon S, Li B, Liu F, Rahman A, Tanimukai H, Grundke-Iqbal I: Tau pathology in Alzheimer disease and other tauopathies. Biochim Biophys Acta 2005, 1739:198-210

87. Goedert M, Spillantini MG, Crowther RA: Tau proteins and neurofibrillary degeneration. Brain Pathol 1991, 1:279-286

88. Schweiger S, Matthes F, Posey K, Kickstein E, Weber S, Hettich MM, Pfurtscheller S, Ehninger D, Schneider R, Krauss S: Resveratrol induces dephosphorylation of Tau by interfering with the MID1-PP2A complex. Sci Rep 2017, 7:13753

89. Vogelsberg-Ragaglia V, Schuck T, Trojanowski JQ, Lee VM: PP2A mRNA expression is quantitatively decreased in Alzheimer's disease hippocampus. Exp Neurol 2001, 168:402-412

90. Zeng LH, Rensing NR, Zhang B, Gutmann DH, Gambello MJ, Wong M: Tsc2 gene inactivation causes a more severe epilepsy phenotype than Tsc1 inactivation in a mouse model of 
tuberous sclerosis complex. Hum Mol Genet 2011, 20: 445-454

91. Santini E, Heiman M, Greengard P, Valjent E, Fisone G: Inhibition of mTOR signaling in Parkinson's disease prevents L-DOPA-induced dyskinesia. Sci Signal 2009, 2:ra36

92. Castellani RJ, Gupta Y, Sheng B, Siedlak SL, Harris PL, Coller JM, Perry G, Lee HG, Tabaton M, Smith MA, Wang X, Zhu X: A novel origin for granulovacuolar degeneration in aging and Alzheimer's disease: parallels to stress granules. Lab Invest 2011, 91: $1777-1786$

93. Laplante M, Sabatini DM: mTOR signaling. Cold Spring Harb Perspect Biol 2012, 4. a011593

94. Pal B, Endisha H, Zhang Y, Kapoor M: mTOR: a potential therapeutic target in osteoarthritis? Drugs R D 2015, 15:27-36 